\title{
Radix Entomolaris with Middle Mesial Canal: A Rare Case
}

\author{
Midhula Sathyan ${ }^{1}$, Baby James ${ }^{2}$, A Devadathan ${ }^{3}$, Minimol K Johny ${ }^{4}$, Manuja Nair ${ }^{5}$
}

\begin{abstract}
Background: Attention to detail with an analytically trained and developed mind is undoubtedly a dental practitioner's most important asset to identify rare and only heard of conditions in patients. Being a field of explosive development due to new technologies, endodontics aids to provide an accurate diagnosis of the complex anatomical variations and conditions of the teeth. Radix entomolaris (RE) is the presence of an additional distolingual $(\mathrm{DL})$ root in the mandibular first molars and its prevalence in the South Indian population is $13.3 \%$. The presence of RE with middle mesial canal (MMC) in the mandibular first molar is a rare experience of the combined occurrence of two uncommon conditions requiring appropriate diagnosis and cautious management. Its management relies on the proper diagnosis and exploration of all the canals, thorough chemomechanical preparation, followed by three-dimensional (3D) obturation without hampering the original root canal anatomy. The appropriate utilization of the advanced aids of magnification and technology, such as the microscopes, loupes, and conebeam computed tomography (CBCT), coupled with the use of thermomechanically treated flexible NiTi files enhances the success in the endodontics while dealing with such rare entities. This article presents a case report of an RE with MMC which is definitely rare in occurrence and requires cautious management.
\end{abstract}

Case description: A 20-year-old female patient was diagnosed with symptomatic irreversible pulpitis with apical periodontitis on the mandibular first molar. It was identified as an RE with MMC on radiographic examination using the Clark's Tubeshift technique. After anesthetizing the tooth using inferior alveolar nerve block, rubber dam isolation was done. The access cavity was prepared and modified distolingually and the canal orifices were located. The MMC orifice was troughed along the groove joining mesiobuccal (MB) and mesiolingual (ML) canals using long shank burs and a sharp DG-16 explorer. The cleaning and shaping procedures were performed carefully to all six canals using NiTi files followed by the 3D obturation.

Conclusion: This case report is a precise description of the effective management of RE with MMC which is a rare entity in our ethnic group. This case was diagnosed using the Clark's Tubeshift technique and managed using magnifying loupe and thermomechanically treated flexible NiTi files. The advanced aids in 3D imaging such as the CBCT, spiral computed tomography (CT), and the magnifying aids such as microscopes coupled with thermoplasticized obturation can accentuate the success rate of such complex morphologies.

Keywords: Mandibular molar, Middle mesial canal, Radix entomolaris.

Conservative Dentistry and Endodontic Journal (2019): 10.5005/jp-journals-10048-0050

"One can be keen in his work and look out for perfection for two reasons, the first being for academic purposes, to explore new territories of knowledge and the second, due to one's nature, for the benefit of human beings, where one looks for perfection so that he can provide the best quality for his fellow being, and I believe the second is the most important and leads to the first."

\section{INTRODUCTION}

Radix entomolaris (RE) is the occurrence of an additional distolingual $(\mathrm{DL})$ root in the mandibular molars. The occurrence of an additional lingual root was first brought to the notice of the world in the literature by Carabelli (1844) and was labeled by Bolk (1915). ${ }^{1}$ The extra DL root was first mentioned by De Moor et al. and was termed as RE. Chandra et al. studied the mandibular first molars in the South Indian population and found the prevalence of RE to be $13.3 \% .^{2}$ The prevalence of these three-rooted mandibular first molars has been reported to be $3.4-4.2 \%$ in Caucasians and $5-30 \%$ in Mongoloids. ${ }^{3-5}$ The extra mesiobuccal (MB) root in mandibular molars was termed as radix paramolaris. The presence of middle mesial canal (MMC) was reported by Vertucci and Williams (1974). The incidence of MMCs accounts for $2.6-10 \%$ of the mandibular first molars. ${ }^{6}$ This case report deals with the management of RE with $M M C$, and the incidence of the combined entity in a single tooth remains unexplored in literature search. The accurate identification of such additional canals is extremely difficult to achieve, and the untreated canals are seen to be associated with periapical pathology in $82.6 \%$
${ }^{1-5}$ Department of Conservative Dentistry and Endodontics, Pushpagiri Dental College, Thiruvalla, Kerala, India

Corresponding Author: Midhula Sathyan, Department of Conservative Dentistry and Endodontics, Pushpagiri Dental College, Thiruvalla, Kerala, India, Phone: +91 9656821809, e-mail: midhulamanas@gmail. com

How to cite this article: Sathyan M, James B, Devadathan A, et al. Radix Entomolaris with Middle Mesial Canal: A Rare Case. Cons Dent Endod J 2019;4(2):44-48.

Source of support: Nil

Conflict of interest: None

of cases. ${ }^{7}$ This article deals with the management of a rare occurrence of RE with MMC in the mandibular first molar.

The main objective of endodontic treatment is the complete removal of the entire vital and necrotic tissues as well as debris from the root canal system and to obtain an intact 3D obturation. The cleaning and shaping procedures being the fulcrum in disinfection, it possesses a great challenge in case of complex root canal anatomies requiring minimal preparation in order to preserve the intervening dentin between these canals. Excessive removal of the tooth material from multiple canals present within a single root can lead to weakening of the radicular dentin. Moreover, increased frequency of fins and communications between canals within the same root acts as a roadblock for complete disinfection 
and the entire treatment becomes challenging and complicated. The occurrence of confluent canals within the same root can even increase the incidence of perforations, ledging, and instrument fractures, leading to treatment failure. Therefore, thorough knowledge about root canal anatomy, proper cleaning and shaping procedures, and obturation techniques are required to combat such situations. ${ }^{8}$

\section{Case Description}

A 20-year-old female patient came to the Department of Conservative Dentistry and Endodontics of Pushpagiri Dental College, with the chief complaint of sensitivity to cold food items and pain while chewing, over the lower right back teeth region. On clinical examination, the right mandibular first molar (46) had deep occlusal caries and was tender on percussion and palpation. On vitality testing, the tooth showed lingering response to cold and delayed response to electric pulp testing. Preoperative radiographs showed coronal radiolucency with pulp involvement and three radiolucent lines were seen till the root apex in the mesial root. An additional distal root was identified by taking another radiograph with $30^{\circ}$ mesial angulation using the Clark's Tubeshift technique (SLOB technique) (Fig. 1). Slight widening of periodontal ligament space around the apical portion of mesial root was also seen and lamina dura remained intact. Based on these findings, the tooth was identified as RE with MMC and the final diagnosis was symptomatic irreversible pulpitis with apical periodontitis. Nonsurgical endodontic treatment was planned, followed by crown placement. Adhering to the principles of ALARA, cone-beam computed tomography (CBCT) was advocated only if the case could not be clinically managed using the magnification aids and digital radiography. ${ }^{9}$

After receiving consent from the patient, the tooth was anesthetized using inferior alveolar nerve block. Under rubber dam isolation, the endodontic access was performed with a no. 2 Endoaccess bur (Dentsply) and the access cavity margins were refined using the Endo-Z bur (Dentsply). Clinical examination was done using the dental loupe (3.5× magnification) and the DG-16 (Dentsply) explorer revealed the distobuccal (DB1), DL, MB, and ML orifices initially. Then the pulp chamber floor was scouted using LN-bur (Dentsply) to locate an MMC orifice along the line joining $M B$ and ML orifices. Similarly a second DB canal (DB2) orifice was located adjacent to the first DB canal (DB1) orifice. All the canals were negotiated and the working length was established using Ingle's radiographic method (Figs 2 and 3 ) and confirmed using apex locator (J Morita Root ZX). Orifices were enlarged using Protaper SX (Dentsply). Cleaning and shaping of all the six canals were done
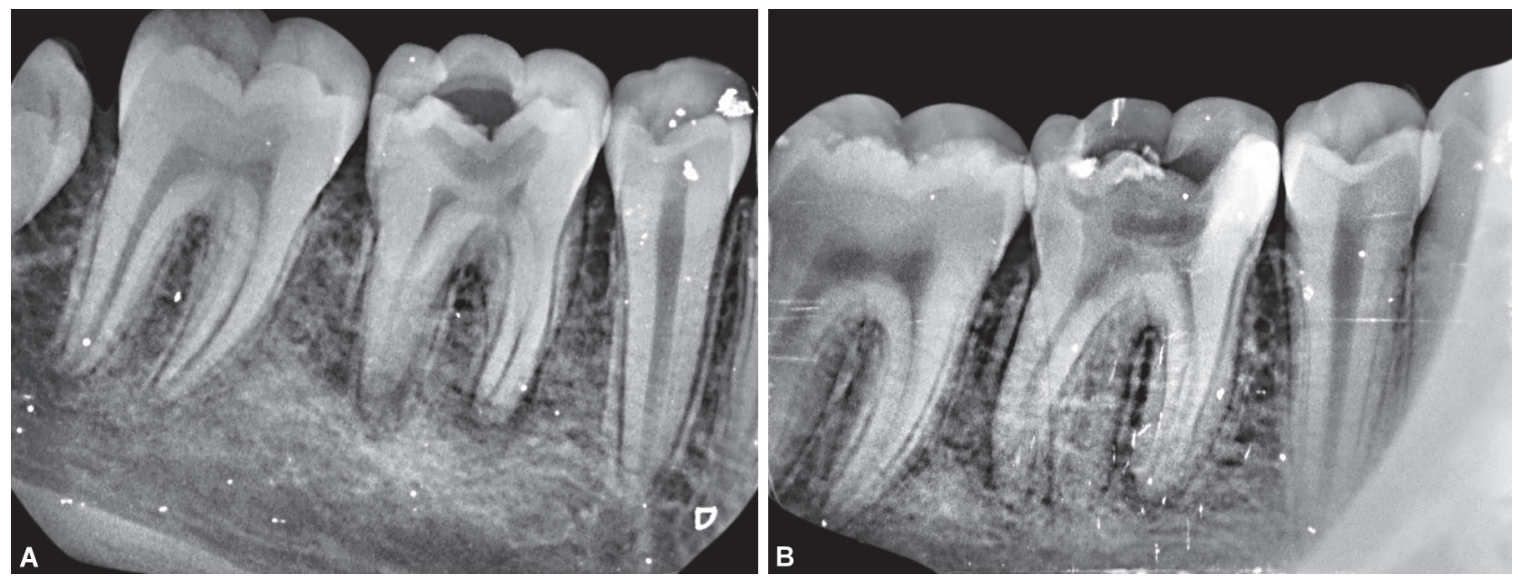

Figs 1 A and B: (A) Preoperative radiograph of 46; (B) Preoperative radiograph: mesial shift 46

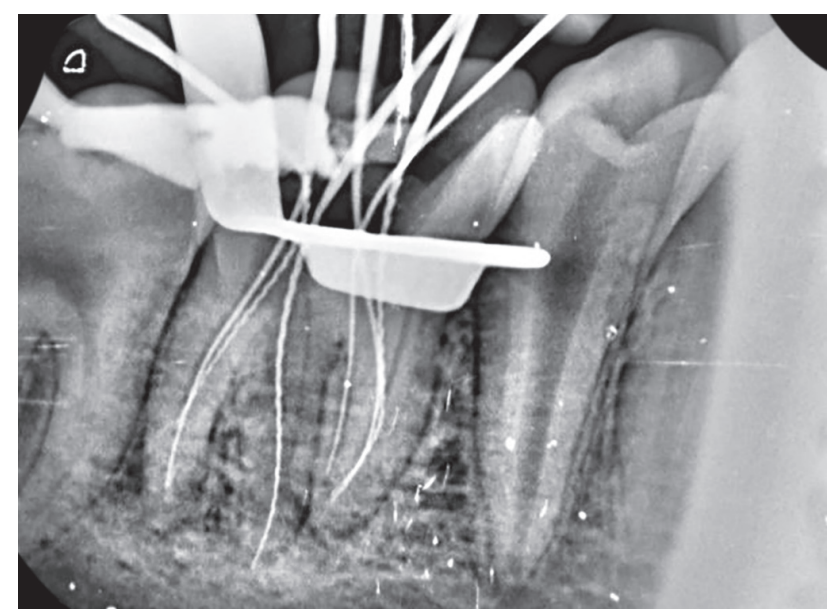

Fig. 2: Working length radiograph of six canals, i.e., three distal canals, namely, DB1, DB2, and DL; and three mesial canals, namely, MB, MM, and $\mathrm{ML}$

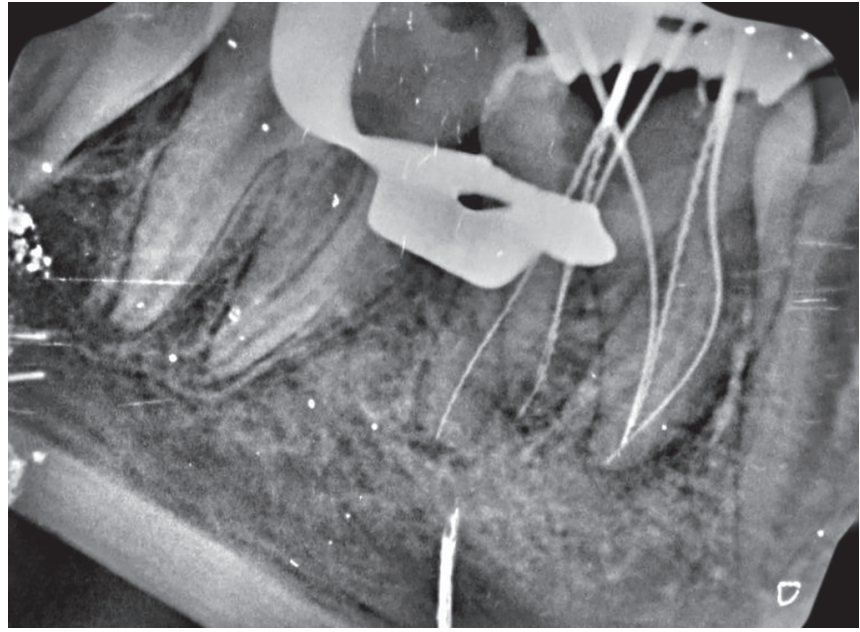

Fig. 3: Working length radiograph-mesial shift confluence of $M L, M M$ and MB canals apically 

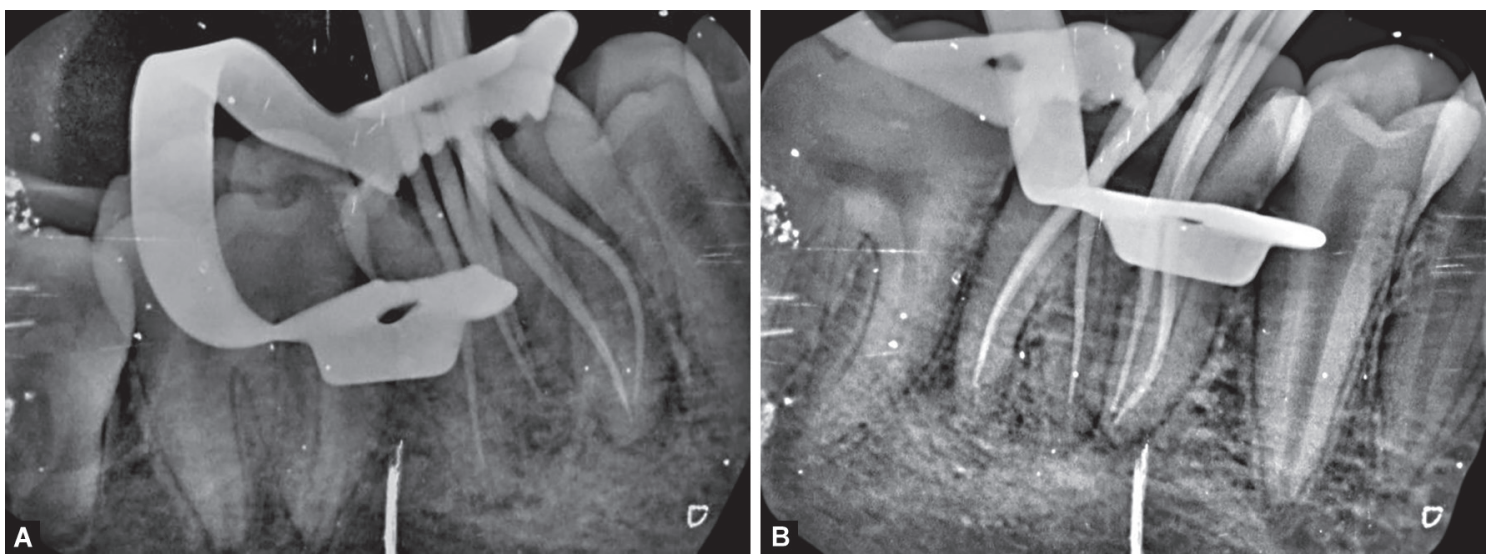

Figs 4A and B: (A) Master cone radiograph, i.e., mesial shift showing combined DB canals; (B) Master cone radiograph showing combined DB canals

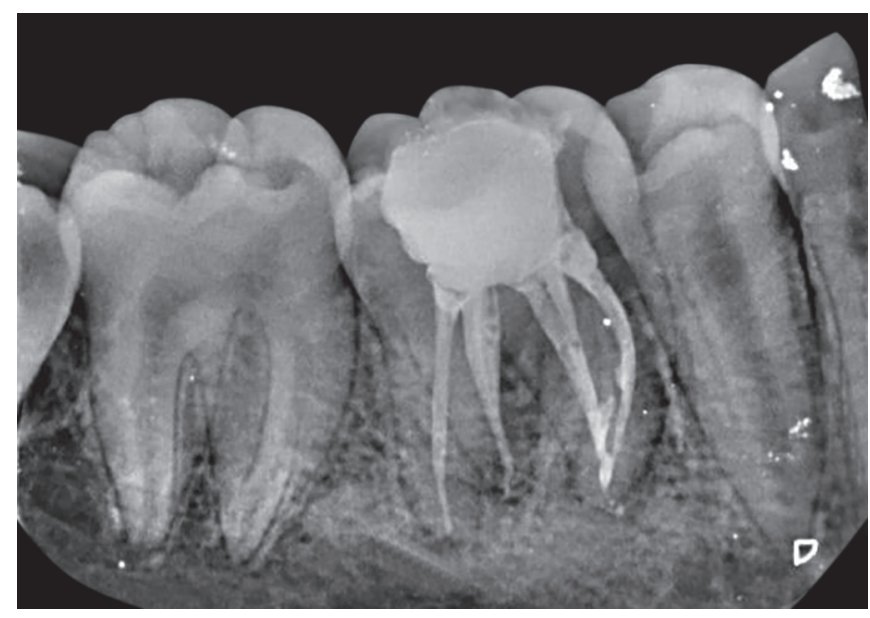

Fig. 5: Distal shift radiograph after obturation showing combined DB1 and DB2 canals in distobuccal root, separate DL root, mesial root with confluence of MB, MM, and ML canals apically

with Protaper gold files upto size F1 (Dentsply) using the crown down technique. The MMC was seen joining with the MB canal at its middle third and the DB2 combined with DB1 canal from its coronal third after enlargement. Sodium hypochlorite of $2.5 \%$ was used during instrumentation. Final irrigation was done using $5.25 \%$ sodium hypochlorite for 1 minute followed by saline and 17\% EDTA solution for 1 minute. Canals were dried using absorbent paper points (Dentsply). Master cone of Protaper size F1 (Dentsply) was selected for all six canals and confirmed using radiographs. Singlecone obturation was done using $\mathrm{AH}$ Plus sealer. Post endodontic restoration was done using composite (Figs 4 and 5).

\section{Discussion}

The success of endodontic management requires a thorough knowledge of root canal anatomy, its proper debridement and disinfection followed by obturation, and intact 3D seal.

\section{Prevalence of Radix Entomolaris}

The prevalence of RE in the mandibular first molars of the South Indian population is $13.3 \% .^{2}$ In population with Mongoloid traits (such as the Chinese, Eskimo, and American Indians), RE occurs with a frequency of $5 \%$ to more than $30 \% .^{10}$ The cause of its occurrence might be due to the various external factors during odontogenesis or presence of an atavistic gene or polygenetic system (atavism is the reappearance of a trait after several generations of absence). Radix entomolaris is commonly seen in mandibular first molars and its bilateral occurrence of $50-67 \%$ has also been reported. ${ }^{5,10}$ The occurrence of RE with MMC in our ethnic group has been very rarely reported in a few case reports, but the prevalence of the combined occurrence of both the entities in a single tooth is not yet reported in literature search.

\section{Morphology of Radix Entomolaris}

In $\mathrm{RE}$, this additional root is located distolingually from the main canal of the distal root. It requires changing the classic trapezoidal access cavity into a more rectangular outline form. Severe root inclination or canal curvature in the apical third of these roots makes instrumentation challenging. Also the frequencies of fins and isthmuses increase among these supernumerary roots, which make both instrumentation and disinfection challenging for endodontists. Broad, flat roots in radiograph are more likely to have multiple canals and intracanal ramifications. Radix entomolaris can either be conical short root or a mature root with normal canal pattern or it can be separate or partially fused with adjacent roots.

In normal radiographs, the $\mathrm{DL}$ root appears to be superimposing on the DB root of mandibular first molars due to which this unusual morphology is often missed out during the diagnosis. On taking the mesial or distal shift of $30^{\circ}$ using the SLOB technique, the separate $D L$ root can be identified in the radiograph. The advanced imaging system of CBCT makes it easier to diagnose such difficult root canal morphologies. Other than radiographical diagnosis, visual inspection of the tooth crown and periodontal probing to analyze the cervical morphology of the roots can promote identification of an additional root. Other morphological variations indicating $R E$ are an extra cusp (tuberculum paramolare), more prominent distal or DL lobe, and cervical prominence or convexity. ${ }^{5}$

A classification of RE was proposed by Carlsen and Alexandersen based on the location of the cervical part of the additional root (Fig. 6). They are of A, B, C, and AC types. Types A and B refer to a distally located cervical part, type $C$ refers to a mesially located cervical part, and type $A C$ refers to the central location of the cervical part in between the mesial and distal root components. ${ }^{11}$ De Moor et al. gave another classification based on the curvature $\mathrm{RE}$ variants in the buccolingual direction. Type I refers to straight root/canals, type II with curvature at the coronal part at the entrance level of the orifice, and type III refers to RE with two curvatures, one at the coronal level and the other at the middle third level. ${ }^{3}$ 

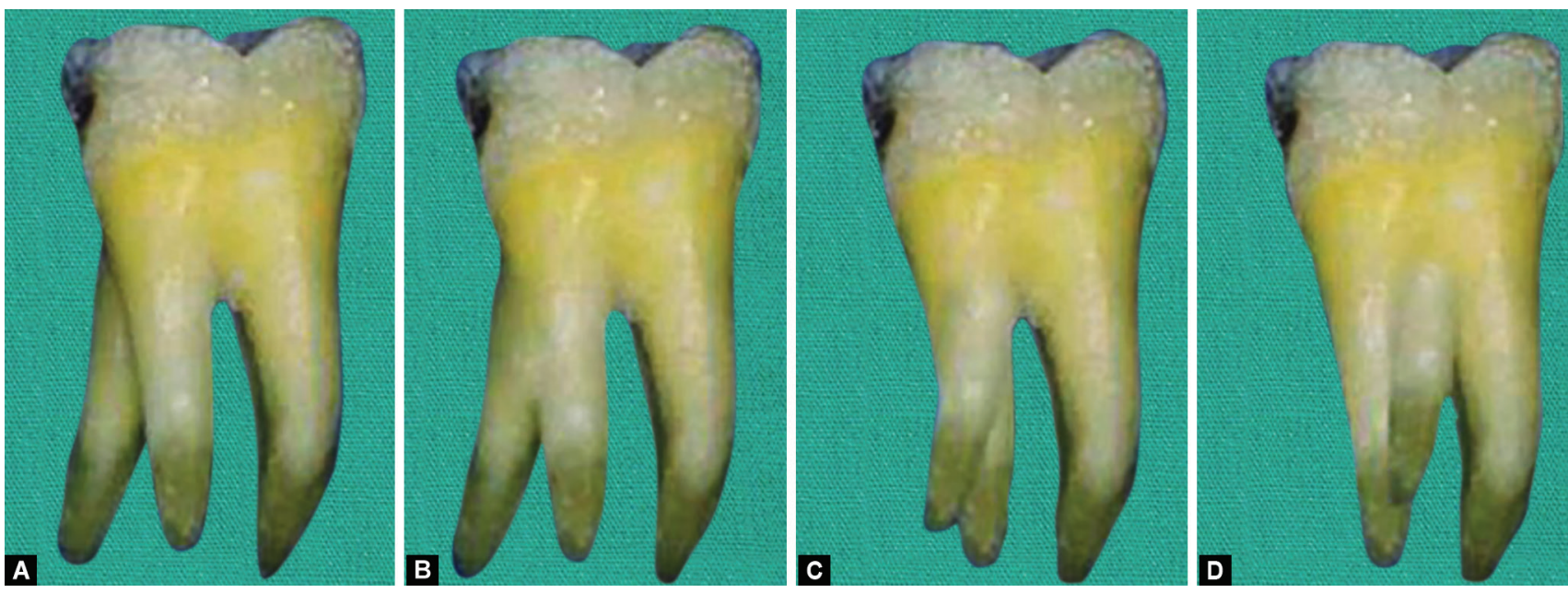

Figs 6A to D: Carlsen and Alexandersen's classification of RE: (A and B) Showing types A and B that refer to a distally located cervical part of the RE with two normal and one normal distal root components, respectively; (C) Type C refers to a mesially located cervical part; (D) AC refers to a central location between the distal and mesial roots ${ }^{11}$
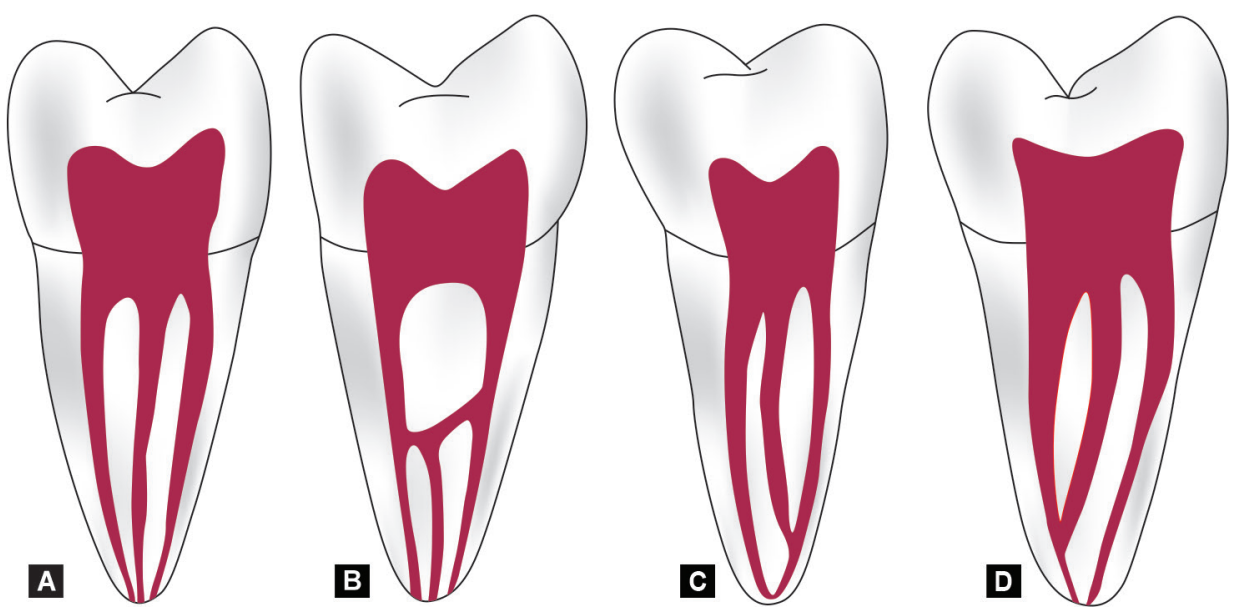

Figs 7A to D: Middle medial mesial canal classification showing: (A) Independent configuration; (B) Fin configuration; (C) Confluent configuration to mesiobuccal canal; (D) Confluent configuration to mesiolingual canal (from Pomeranz et al. ${ }^{14}$ )

\section{Occurrence of Middle Mesial Canal and Additional Distal Canal}

Fabra-Campos and Bond reported the presence of three mesial canals $^{5,6}$ and Stroner stated the presence of three distal canals. ${ }^{12}$ Vertucci in 1984 found 1\% MMCs in permanent mandibular first molar in his in vitro study. Ahmed et al. stated a prevalence of $4 \%$ of MMC using clearing technique. ${ }^{13}$ Pomeranz et al. classified (Fig. 7) MMC into the following three morphologic categories: fin, confluent, and independent. In fin, there is free communication between all three canals; and in confluent, MMC joins one of the main canals. Yesilsoy et al. in a study reported that the groove between the MB and ML can be as deep as $3.5 \mathrm{~mm}$ from the orifice and between $4 \mathrm{~mm}$ and 6 $\mathrm{mm}$ from the apical foramen. This groove being the potential area to be addressed requires cautious probing to get a "catch" or a "sticky" feeling if there is a canal orifice within the isthmus. ${ }^{14,15}$ Navarro et al. stated that the preparation of a "canal" in the isthmus area has an additional advantage of dividing the isthmus for easier cleaning and disinfection. ${ }^{16}$ Maintain caution while instrumenting confluent canals with nickel-titanium rotary instruments, since they may fracture where the two canals join at a sharp angle into one small canal.

\section{Clinical Approach in Addressing Additional Canals}

Once the additional canals are diagnosed, the access cavity preparation has to be modified for addressing them. Long shank burs, ultrasonic tips, and a sharp DG-16 explorer are inevitable to locate them. The straight line access is essential to maintain patency while measuring working length as well as during the canal preparation to avoid ledging, straightening of canals, transportation, zipping, lateral strip perforation, and instrument fracture. Further, while cleaning and shaping multiple interconnected canals within the same root, complete disinfection with minimal canal enlargement in order to preserve the intervening dentin is an endodontic challenge. This challenge can be met only by thorough knowledge of root canal anatomy as well as adequate training and skill. The use of advanced 3D imaging aids such as $C B C T$, magnifying aids such as loupes and dental operating microscopes, appropriate techniques for exploration, biomechanical preparation using different NiTi systems, and the 3D obturation using injectable gutta-percha can make its management more easier. 


\section{Conclusion}

Radix entomolaris with $\mathrm{MMC}$ is an extremely rare entity in our ethnic group. The 3D imaging aids such as CBCT and magnifying aids such as microscope and loupes will help in the proper diagnosis and successful management of such complex morphologies. The skill as well as knowledge in its complete debridement, thorough disinfection, and obtaining 3D seal of the entire preparation adds to the success in endodontics.

\section{References}

1. Carabelli G. Systematisches Handbuch der Zahnheilkunde. 2nd ed., Vol. 1844, Vienna: Braumuller und Seidel; 1844, p. 114.

2. Chandra SS, Chandra S, Shankar P, et al. Prevalance of radix entomolaris in mandibular permanent first molars: a study in South Indian population. Oral Surg Oral Med Oral Pathol Oral Radiol Endod 2011;112(3):e77-e82. DOI: 10.1016/j.tripleo.2011.02.016.

3. De Moor RJG, Deroose CAJG, Calberson FLG. The radix entomolaris in mandibular first molars: an endodontic challenge. Int Endod J 2004;37(11):789-799. DOI: 10.1111/j.1365-2591.2004.00870.x.

4. Tratman EK. Three-rooted lower molars in man and their racial distribution. Br Dent J 1938;64:264-274.

5. Calberson FL, Moor RJDee, Deroose CA. The radix entomolaris and paramolaris: clinical approach in endodontics. J Endod 2007;33(1): 58-63. DOI: 10.1016/j.joen.2006.05.007.

6. Teixeira FB, Sano CL, Gomes BP, et al. A preliminary in vitro study of the incidence and position of the root canal isthmus in maxillary and mandibular first molars. Int Endod J 2003;36(4):276-280. DOI: 10.1046/j.1365-2591.2003.00638.x.
7. Baruwa AO, Martins JNR, Meirinhos J, et al. The influence of missed canals on the prevalence of periapical lesions in endodontically treated teeth: a cross-sectional study. J Endod 2019; 1-6.

8. The Root Canal Anatomy in Permanent Dentition Versiani MA, Basrani Bettina, Sousa-Neto MD 1st ed., Springer International Publishing; 2019.

9. De Toubes KM, Côrtes MI, Valadares MA, et al. Comparative analysis of accessory mesial canal identification in mandibular first molars by using four different diagnostic methods. J Endod 2012;38(4):436-441. DOI: 10.1016/j.joen.2011.12.035.

10. Yew SC, Chan K. A retrospective study of endodontically treated mandibular first molars in a Chinese population. J Endod 1993;19(9):471-473. DOI: 10.1016/S0099-2399(06)80536-4.

11. Carlsen O, Alexandersen V. Radix entomolaris: identification morphology. J Dent Res 1990;98(5):363-373. DOI: 10.1111/j.16000722.1990.tb00986.x.

12. Stroner WF. Mandibular first molar with three distal canals. Oral Surg 1984;57(5):554-557. DOI: 10.1016/0030-4220(84)90316-5.

13. Ahmed HA, Abu-Bakr NH, Yahia NA, et al. Root and canal morphology of permanent mandibular molars in Sudanese population. Int Endod J 2007;40(10):766-771. DOI: 10.1111/j.1365-2591.2007.01283.x.

14. Pomeranz HH, Eidelman DL, Goldberg MG. Treatment considerations of middle mesial canal of mandibualr first and second molars. J Endod 1981;7(12):565-568. DOI: 10.1016/S0099-2399(81)80216-6.

15. Singh S, Mirdha N, Arora R, et al. A rare case report series of radix entomolaris with middle mesial canal in permanent mandibular first molar. International Journal of Current Advanced Research 2018;07(1):9411-9414.

16. Navarro LF, Luzi A, Garcia AA, et al. Third canal in the mesial root of permanent mandibular first molars: review of the literature and presentation of 3 clinical reports and 2 in vitro studies. Med Oral Patol Oral Cir Bucal 2007;12(8):E605-E609. 